\title{
LA INTERTEXTUALIDAD: UN ENSAYO METACRÍTICO
}

\author{
María Amoretti Hurtado
}

\begin{abstract}
RESUMEN
El objetivo del artículo es hacer sociocrítica de la intertextualidad como un término clave en la crítica contemporánea. Se esbozan las condiciones que posibilitaron su emergencia y la descripción de sus zonas de impacto, es decir, de sus contradicciones internas. Además, se examina la intertextualidad como parte de una política cultural, como la emergencia de una noción que va más allá del paradigma global en el que se inscribe el saber general.
\end{abstract}

\begin{abstract}
This article makes sociocriticism of intertextuality a key term in contemporary criticism. It outlines the conditions that allowed its emergence and describes areas of impact or internal contradictions. Furthermore, it examines intertextuality as part of a cultural policy or the emergence of a notion which goes beyond the global paradigm that encloses general knowlege.
\end{abstract}

Me propongo reseñar, desde un punto de vista teórico, el desarrollo y los alcances del concepto de intertextualidad durante la presente centuria.

Ciertamente, el término "intertextualidad" se ha convertido en un término popular en la práctica literaria y constituye, no solo un campo metodológico, sino también, una estrategia de escritura consciente entre los mismos escritores.

No obstante, abundan las contradicciones en su definición y, entre los trabajos que he podido escuchar durante el Simposio de Paraguay sobre este tema en 1991, esas deficiencias de concepto y aplicación se observan notoriamente.

Para ordenar de algún modo los diferentes modos de pensar la intertextualidad, Vulture ha establecido tres orientaciones básicas ${ }^{1}$ :

a) La intertextualidad como factor de transformación.

(Kristeva - Derrida - Barthes - Sollers) 
Aquí la intertextualidad es la base misma de la generatividad del texto. El texto es transtextualidad infinita, una red de textos que se superponen e interceptan. La significancia es el movimiento transformador de los intertextos.

b) La intertextualidad como hipercodificación.

(Eco)

Esta dirección pone énfasis en los aspectos metacomunicacionales que orientan al lector en el modo de recepción y consumo del texto.

La competencia intertextual se convoca en el interior del texto bajo la forma de esquemas narrativos o retóricos que, una vez reconocidos por el lector, orientan su actividad de desciframiento según un principio de expectativas satisfechas o frustradas. La intertextualidad se acerca aquí a una especie de convención discursiva que remite a modalidades genéricas, de modo que es más bien un enfoque pragmático de lo intertextual.

c) La intertextualidad como organización participativa del lector en la construcción del texto.

(Riffaterre)

La intertextualidad orienta la lectura del texto y establece una referencialidad cruzada, de modo que una lectura lineal no es posible, sino de volumen. Vista así, la lectura es una dialéctica memorial entre el texto que el lector descifra y los textos que el lector recuerda.

La intertextualidad es pues, un efecto de percepción del texto como de las variantes posibles de una invariable.

\section{En resumen}

El intertexto, según estas tres orientaciones, puede ser:

a) factor de producción o transformación,

b) marca pragmática de descriframiento,

c) huella reconocible en la percepción del texto a partir de la cual se orienta la lectura.

Decía que el concepto de intertextualidad ha desarrollado no solo un campo metodológico, sino también, una estrategia de escritura consciente entre los propios escritores. En el medio costarricense, el escritor que lo ha empleado como tema y lo ha puesto en la escena del texto, es Rafael A. Herra en el relato titulado El genio de la botella ${ }^{2}$.

Su utilización es tan ilustrativa en el texto de Herra, que ninguna de las tres orientaciones queda por fuera. Es mi opinión, que entre los tres modos de percepción del intertexto no hay exclusión y se debe hacer un esfuerzo por trabajarlo en las tres perspectivas ${ }^{3}$.

\section{Importancia del concepto en la teoría literaria moderna}

Esta noción es la mayor responsable de la ruptura epistemológica en relación con la crítica tradicional. Es la intertextualidad la que ha generado una redefinición del escribir y del 
leer y, por tanto, solo a partir de ella se puede extender el concepto de texto como red, como fenómeno reticular. Si bien se origina en el pensamiento de Bajtín, su desarrollo en la crítica moderna no sigue necesariamente las mismas orientaciones, objetivos que su creador le asignó inicialmente.

\section{Proyecciones del concepto}

Nuestra práctica, sea como críticos o como creadores, se inserta en una totalidad mayor, cual es la sociedad. Por lo tanto, habría que preguntarse: ¿Qué aporte podemos hacer a la cultura de nuestro tiempo y a la que vendrá con una teoría literaria intertextual? ¿Qué importancia tiene como proyección más allá del pequeño territorio en que nos movemos los que vivimos de este oficio?

Para responder a estas interrogantes es, pues, menester, desbordar nuestra propia esfera y rastrear en los círculos que incitan nuestro saber desde dimensiones epistemológicas superiores. Es nuestra labor, entonces, identificar las condiciones de posibilidad de la emergencia del concepto de intertextualidad en el contexto mayor: su propia época. Reflexionemos.

La intertextualidad aparece en los comienzos de este siglo, pero no es integrada a los paradigmas de la época, sino hasta la segunda mitad de la centuria.

La primera en difundirlo es Kristeva. Ella toma el concepto bajtiano y construye, a partir de él, una teoría de la escritura en la que el intertexto es espacio de transformaciones y este concepto de transformación unido al de proceso, es la episteme básica de los tres nudos en que se aglutina hoy el poder literario: texto, escritura y lectura.

La fuerza transformadora de la percepción intertextual hace de la literatura el territorio de la no exclusión, de ahí que ahora las oposiciones no representan incompatibilidades sino posibilidades de nuevas manifestaciones. Este paisaje epistemológico, normalmente se vincula a Europa, sino recordemos los autores que hemos señalado de paso al inicio de este artículo, y con ese gesto caemos en un lamentable olvido, pues hay un latinoamericano que, sin conocer a Bajtin, elabora una poética que adelantándose a todas estas teorías literarias, se constituye para los teóricos y filósofos europeos en la referencia obligada. Nos referimos a Jorge Luis Borges. Y haciendo caso omiso de cualquier pensamiento de provincialismo cultural, en la figura de Borges, Latinoamérica ha contribuido grandemente en la constitución de los modernos paradigmas de teoría literaria. No en vano Alfonso Toro define a Borges como el iniciador del posmodernismo, no solamente en Latinoamérica, sino en general.

$\mathrm{Al}$ igual que la de Nieztsche, la obra de Borges es una profecía, un adelanto del futuro que se puede leer desde sus primeros "ejercicios narrativos" como él mismo llamó a los textos que luego se publicaron bajo el título de Historia Universal de la Infamia 4 .

Es precisamente por su carácter anticipativo que la obra de Borges fue durante tanto tiempo incomprendida. Y, ¿cuál podríamos decir sería el rasgo sintético y englobante más caracterizador de la literatura borgiana sin la intertextualidad y la deconstrucción? ¿Cómo entender el texto borgiano sino como un proceso en el que flexionándose sobre sí misma, la escritura incita a una lectura productora? 
Pero tanto la posmodernidad borgiana como la que debe entenderse universalmente, no es sino la evolución de la misma modernidad y sus paradigmas. Un cierto hartazgo de sus conocimientos y la creciente desilusión de sus resultados: un mundo en el que la ciencia y la tecnología sobre las que la humanidad había sentado sus esperanzas, se han vuelto de frente al mismo hombre para destruirlo; un mundo en el que la organización política, en vez de ofrecerle el bienestar prometido, ha entronizado macroestructuralmente la pobreza. Estado, ciencia y tecnología, una triada sostenida en el más preclaro racionalismo, no convencen hoy a nadie y las mayores evidencias de la disconformidad están en la luchas pacifistas, feministas y en las protestas ecológicas. En esta crisis de la ratio sobre la que se funda el mundo moderno como lo mostró escandalosamente Foucault hará apenas unas décadas, la imaginación y la intuición ganan terreno. Ya no se trata de ver cartesianamente de modo claro y distinto, sino de relativizar lo que hasta hoy se nos había ofrecido como claro y distinto. Se trata de una percepción inédita que quizá se halle más cerca de la literatura que de cualquier otro modo cognoscitivo, sobre todo cuando se piensa en ella como intertextualidad y como dialogismo. Veamos cómo.

Si la modernidad se ha caracterizado por el paradigma excluyente, la metáfora de la barra en el fenómeno binario, la posmodernidad podría interpretarse como la búsqueda de la armonía y de la integración. Pero no a la manera de una dialéctica hegeliana, sino a la manera de la dialógica bajtiana, capaz de reunir las otredades sin que cada una de ellas deje de ser lo que es. Así, la intertextualidad es un discurso a dos voces: las del antes y el ahora, la del tú y del yo, la del aquel y de este, la de allá y aquí, la de tu verdad y la mía. Y en la coexistencia de las otredades, en la que ninguna es objeto de la otra, podríamos encontrar el resquicio apenas justo para salvar al hombre de la confabulación. en la que inconscientes, ideología y lenguaje, se han aliado al poder para darle muerte.

La intertextualidad no debe ser entendida, como tampoco debe ser entendido el posmodernismo, como una lucha contra la racionalidad, sino más bien, como la búsqueda de otro modo de racionalidad que nos permita ex-centrarnos para ser capaces de percibir en sus bordes, los límites que la definen, el borde que nos recuerde siempre sus propios límites.

Foucault ha sido el contemporáneo que ha demostrado que este camino es posible. Quien mejor ha descrito y aplicado este modo cognoscitivo nuevo es Foucault en su método del discurso. Ha confesado que su arqueología del saber es una hermenéutica o análisis que él ha aprendido en el análisis literario. Así, en 1963, afirma que de lo que se trata es “(...) de establecer, de una obra a otra, una relación visible y nombrable en cada uno de los elementos y que no sea de orden de la semejanza (en toda la serie de nociones mal pensadas y a decir verdad, impensables, de influencia, imitación) ni tampoco del orden de la sustitución (de la sucesión del desarrollo de las escuelas): una relación tal que las obras puedan definirse unas a otras frente, al lado y a distancia de las otras, apoyándose a la vez en su diferencia y simultaneidad, y definiendo sin privilegio ni culminación la extensión de una red." 5

Así, más que una ruptura, la intertextualidad se marca en esta centuria como un consenso que va más allá del paradigma teórico literario, elevando éste a un paradigma global en el que se inscribe el saber general dándole a este un ritmo y un sabor poéticos y un mismo derrotero y búsqueda: la comunicación. 
No muy lejos de esta optimista apología de la noción y sus efectos de consenso dialógico, que fue precisamente la que privó en el IX Simposio de Literatura en Asunción, está el punto de vista de Manfred Pfister, aparecido en uno de los números de Criterios. 6

Para justificar este lado "oscuro" de los efectos intertextuales, Pfister lo refiere como una consecuencia de las propias contradicciones internas de la "Posmodernidad". Resumo sus ideas: el posmodernismo es una noción que nace por la necesidad de un nuevo concepto para nuevos espacios de contemporaneidad.

En general, se puede decir que hay tres visiones generales de posmodernismo:

a) (Esc. de Bauhaus). Toma a la arquitectura como su paradigma y considera el posmodernismo como un movimiento revisionista, un intento de deshacer el modernismo y regresar a un estilo sincrético que mueve a repetir las formas arquitectónicas de períodos anteriores e incluso vuelve a emplear el ornamento.

b) (Leslie Fiedler). Se trata de una ruptura con el modernismo como una ruptura con el pasado. Es una revuelta orientada hacia el futuro y se enraíza en las mitologías triviales de los medios masivos y la cultura popular.

c) (Ihab Hassan. Gerald Graff, Jean F. Leyotard). Es la lógica extensión y culminación del modernismo como una vuelta adicional y final de la tuerca del proceso de modernización que comenzó en el siglo XIX, si no antes.

A las tres versiones las une el carácter parasitario: una especie de "mise en scéne" de materiales y procedimientos dados de antemano. Esto se debe a su propio contexto: un mundo de contradicciones, ecológicas e ideológicas, un mundo contingente y fortuito; en un nivel de conciencia que ya no nos permite considerar la realidad como algo que ha de ser experimentado de manera directa e inmediata, puesto que la realidad siempre nos llega preestructurada, pre-formada por el lenguaje y la cultura. Es este contexto el que hace surgir una estética de la cita, de la parodia y del travesti que juega sus juegos con los sobrantes de la herencia cultural y los desperdicios de la industria cultural.

Así, para John Barth (Perdido en la casa de los espejos), ya el arte no puede ser un simple reflejo de la realidad, pues nuestros espejos son distorsionadores que reflejan otras imágenes en el espejo. Realidad -páramo de espejos. El arte -y la literatura en particulardeviene un reciclaje de material de desecho más que un acto de creación. El arte es una tecnología del saber simbólico gastado. Un reciclaje de desechos semánticos.

Para Barth, la intertextualidad genera una literatura de agotamiento. La originalidad sobrevive en forma de juegos sofisticados con los textos existentes y las estructuras tradicionales, en forma de alusión, cita, parodia y collage.

Raymond Federman ha acuñado para esto un término "playgarism" que significa una combinación de lo lúdico con lo intertextual; plagio juguetón y consciente de sí.

La intertextualidad se ha convertido en la marca de fábrica del modernismo: repetir interminablemente y de maneras siempre nuevas lo que ya ha sido pensado y dicho antes. Es la expansividad, una reacción en cadena que intenta desenmarcar todas las nociones de autonomía y unidad del sujeto y del texto como funciones ideológicas. 
Se trata de una política cultural que propaga la relatividad de cada posición individual, la autocrítica de cada palabra, el socavamiento de todo monologismo dogmático y oficial, la profanación carnavalesca de todo lo sagrado y la subversión de toda autoridad.

\section{La intertextualidad posmodernista}

La intertextualidad en el marco de la posmodernidad, no es solamente un procedimiento, sino que es el genotexto mismo, el principio constructivo central; es puesta en primer plano, exhibida, tematizada y teorizada. Está teóricamente conceptualizada dentro de los textos mismos.

Es una literatura autoconsciente (cocinada/cruda), autoreflexiva, una literatura que tiene su origen en los seminarios universitarios y les vuelve a proporcionar a éstos material nuevo para análisis e investigación.

"Poetae docti" modernos que producen textos literarios y textos críticos al mismo tiempo, que reflexionan unos sobre otros. Una especie de metatexto que intenta destruir la distinción entre discurso poético y discurso teórico.

\section{Blancanieves de Barthelme: Estética modernista estadounidense}

La intertextualidad en ese contexto ha producido una "literatura del rellenamiento que estimula los sofisticados placeres de lo dispar y lo heterogéneo".

Celebra que todo sea desechable al azar y compite alegremente en su abundancia heteróclita con los catálogos de encargo por correo, los estantes de los supermercados, los canales de los medios masivos, y las modas febrilmente cambiantes del empaquetamiento, la publicidad y el vestuario. Se asocia al propósito del consumismo ${ }^{7}$ y de la industria del entretenimiento. Una maniobra de ingeniería social que nos ayuda a reprimir nuestras angustias en lo tocante a la disminución de los recursos naturales mediante la estimulación de una euforia artificial de la abundancia.

En este panorama de juicios contrarios sobre la noción de intertextualidad, hemos hecho metacrítica, pues hemos procedido a un análisis sociocrítico de un elemento utilizado por la sociocrítica; es decir, nos hemos esforzado por esbozar las condiciones que posibilitan la aparición del concepto de intertextualidad, por una parte, y por otra, hemos descrito sus zonas de impacto, es decir, sus contradicciones internas y sus antagonismos discursivos: su interdiscursividad.

Vulture es la primera en discernir vertientes diversas para la comprensión del concepto y si bien pueden aceptarse como complemetarias, esta aceptación es posible justamente por que las tres vertientes señaladas por Vulture responden de algún modo a actitudes hacia la realidad contemporánea. Pfister profundiza más en el caleidoscopio valorativo de la noción y la define como un producto de la contemporaneidad posmoderna y, como tal, tributaria del mismo mar de contradicciones que constituyen el contexto en que tiene lugar su emergencia. 
En otras palabras, la intertextualidad lleva al campo de la significación, los riesgos vacilantes de la noción posmodernista. Reitero:

1. Una tendencia progresista que genere una respuesta correctiva frente a los males de la modernidad.

2. Tendencia falsamente proyectiva, pues se piensa la posmodernidad como una voluta adicional y final de la tuerca del proceso de modernización, es decir, una acentuación de las consecuencias negativas de éste.

En el primero de los casos, el aporte de nuestro dominio del saber consistiría en sacar partido del relativismo entronizado haciendo de él un verdadero antídoto contra los dogmatismos, para dar paso a un nuevo concepto de dialógica, más genuino, más auténtico y respetuoso de la condición de sujeto del otro.

En el segundo de los casos, el ámbito de nuestro saber sería el propulsor más responsable de una significosis tan aguda que rompería todas las correlaciones posibles entre los códigos, produciría una catástrofe semiótica increíble en la que la consecuencia menor sería la absoluta pérdida de todo sentido: el delirio del absurdo más insostenible.

Como se ve, al igual que en la biotécnica o el manejo de los reactivos nucleares, en nuestro campo se administra material de una alta peligrosidad, y oscilamos constantemente entre dos grandes extremos.

Por eso, si como se afirmó en Asunción, que la intertextualidad podría elevar el paradigma teórico literario a un paradigma global en el que se inscribe el saber general, gracias a su implícita invitación al diálogo y a la escucha polifónica; entonces, la intertextualidad sería una contribución a la armonía y al consenso en este mundo de crisis en que vivimos. Si esto fuera posible, la intertextualidad sería el modus operandi de una forma de comunicación y de una episteme diferente frente a los signos, como lo quiere Bajtín cuando habla de responsabilidad.

Desgraciadamente, la intertextualidad también ha generado un proceso involutivo como el descrito en el segundo caso. Esto es, una acentuación de las marcas negativas de la modernidad, elevando la práctica y la psicología consumista a rango estético.

Quedaría pendiente el devolver la noción de intertextualidad al pensamiento de Mijail Bajtín, para determinar el lugar que ocuparía en el sistema explicativo de su creador y determinar así su valor. Este último esfuerzo reviste especial interés, pues necesariamente implica un examen de la fuerza de las metrópolis hegemónicas y su inteligencia sobre las prácticas literarias de los subcontinentes y su eventual impacto en las búsquedas identitarias de los pueblos y culturas marginadas. Esto lo dejaremos, pues, para otra oportunidad.

\section{Notas}

1. Referimos, para un detalle completo de la revisión de Vulture a nuestro artículo "La intertextualidad como ruptura en el discurso literario". Káñina. 
2. Remitimos a un artículo nuestro publicado en Káñina, titulado "Tres niveles intertextuales por los seis lados del cubo de la escritura". En él examinamos prolijamente los tres modos de apropiación y elaboración del concepto de intertextualidad en el mencionado libro de Herra.

3. Tanto el análisis de Vulture como el mío en este artículo se refieren a una evaluación de la intertextualidad tal y como opera en la crítica actual, también llamada poscrítica. No estoy considerando la adecuación del concepto en relación con su creador, me refiero a Bajtín y el modo en que éste lo concibió originalmente. En todo caso, esa discusión está apenas por iniciarse y su mayor obstáculo es el problema de las traducciones y las autorías.

4. Remitimos a la tesis de maestría: Historia universal de la infamia: Subversión de un discurso narrativo, que bajo nuestra dirección presentó Oscar Montanaro en la Universidad de Costa Rica en 1988 y de la cual se han publicado varios artículos, los que destacan sobre todo la preocupación intertextual de la obra de Borges.

5. In Tel Quel, Theórie de l'Ensemble, París: Seuil, 1963.

6. Criterios. 29. Enero-junio, 1991. La Habana.

7. Entiéndase por "consumismo", la noción que da Eco en La estrategia de la ilusión: "Más de lo que estamos habituados a tener, más de lo que jamás podríamos desear, que habrá hasta para tirar". Barcelona: Lumen. 1986. (pág. 20).

\section{Bibliografía}

Amoretti, María. "Tres niveles intertextuales por los 6 lados del cubo de la escritura". Káñina. "La intertextualidad como ruptura espistemológica". Káñina.

Eco, Umberto. 1986. La estrategia de la ilusión. Barcelona: Lumen.

Kristeva, Julia et. al. 1963. Theorie d'ensemble. Paris: Seuil.

Montanaro Oscar. 1988. Historia universal de la infamia: Subversión de un discurso narrativo. Tesis de Maestría: Universidad de Costa Rica.

Pfifter, Manfred. 1991. “Cuán posmoderna es la intertextualidad?”. Criterios. 29(1). 